\title{
EXPERIMENTS WITH ACCURACY OF THE AIR ION FIELD MEASUREMENT
}

\author{
P. Fiala ${ }^{1}$, M. Steinbauer ${ }^{2}, K$. Bartušek $^{3}$, Z. Szabó ${ }^{4}$ \\ 1,2,4) Department of Theoretical and Experimental Electrical Engineering, Brno University of Technology, Kolejni 4, \\ 61200 Brno, Czech Republic, fialap@feec.vutbr.cz,www.feec.vutbr.cz/utee \\ ${ }^{3)}$ Institute of Scientific Instruments, Academy of Sciences of the Czech Republic, Královopolská 147, 61264 Brno, \\ Czech Republic, bar@isibrno.cz, http://www.isibrno.cz
}

\begin{abstract}
Summary This article presents the capability of methods for measuring of the air ion concentration and principles of ion spectral analysis methods. The analysis of the electric state of air shows the presence of various ion sorts. The therapeutic effect of negative high-mobility ions of proper concentration is known. This positive effect was observed in caves that are used for speleotherapy.
\end{abstract}

\section{INTRODUCTION}

Electrical phenomena occurring in ionized gases involve physical-chemical-biologically reactive ions, radicals, and molecular species. These phenomena are encountered and overlap among diverse fields of chemistry, physics, engineering, meteorology, climatology, medicine, microbiology, physiology and industrial hygiene. The physical and chemical aspects of small air ions and radicals have been under investigation almost from the discovery of electricity. Plasma chemistry and discharge physics are inexorably intertwined. The health implications of air ionization have been reviewed elsewhere [1][5]. Improved diagnostics and mechanistic understandings of electrical discharges in gases [6][7] have led to the development of engineered devices with highly controllable processes for the generation of non-thermal plasmas in the treatment of chemical [8], [26], [27] and biological contaminants [9]-[12]. Coupled with the increased interest in controlling the potpourri of airborne contaminants, there has been an awakening kindled in applying this technology for improving the air quality of enclosed indoor environments [13]-[17].

It is known the effect of negative ions to human healthy. The presence of negative air ions in an inhaled air is necessary for the normal vital activity of animals and humans [18]. Clean rural air contains some hundreds to some thousands negative air ions in a cubic centimeter. It has been established that during a long stay in closed rooms, people experience a deficit of the negative air ions, the socalled oxygen "starvation." It causes a worsening of a health condition and predisposes to the development of diseases [2], [19]. In the 1930s, A. L. Tchijevsky suggested compensating for the negative air ions deficiency by an electric ionization of air [19]. The problem of an artificial ionization of air remains urgent also at present. The indoor air in hospitals and offices where many people are present, as well as in air-conditioned rooms, contain, in the best case, as little as tens or hundreds of charges in a cubic centimeter, and the level of the negative air ions can fall even to zero [20]. It was shown by A. L. Tchijevsky [19], [21] and later by N. I. Goldshtein [22] that the complete absence of the negative air ions in the inhaled air is fatal to animals. Modern devices generate the negative air ions in different quantities, from a few hundreds to thousands and millions ions per cubic centimeter. These devices are used for both cleaning the air from dust, microbes, and volatile admixtures by high doses of the negative air ions [23] and enriching the air by the negative air ions for prophylactic and therapeutic purposes.

The Department of the Theoretical and Experimental Electrical Engineering of Brno University of Technology and the Institute of Scientific Instruments of the Academy of Sciences of the Czech Republic are involved in the research of ion field in office and living spaces [24], [25]. The objective is to increase the concentration of light air ions in these spaces. Another task is to set up a simulated therapy room, with conditions similar to speleotherapy caves. It sets the requirements for accurate measurement of the ion fields with good repeatability. The article deals with the design of gerdien condenser and peripheral measuring devices. An optimal design is important for eliminating the inaccuracy of ion concentration measurement.

\section{MEASURING METHOD}

Several methods are currently used to measure air ion fields: The dispersion method, the ionspectrometer method, the Faraday cage method, and the gerdien condenser method, whose principle is shown in Fig. 1.Here is $d_{1}-$ inner electrode diameter, $d_{2}$ - outer electrode diameter, $l$-length of gerdien condenser, $M-$ air flow volume rate, $v-$ air flow velocity, $e$ - elementary charge of electron, positive air particle (ion), negative air particle (ion).The gerdien condenser consists of two electrodes. There is an electric field between the inner electrode (the collector) and the outer electrode. The field is imposed by voltage source U. Air ions flow from the fan through the gerdien condenser. Negative ions in the electric field impact 
the collector, and the current produced is measured by a pA-meter [24]. The current which is measured is proportional to air ion concentration. The model of the measuring system was presented in [25].

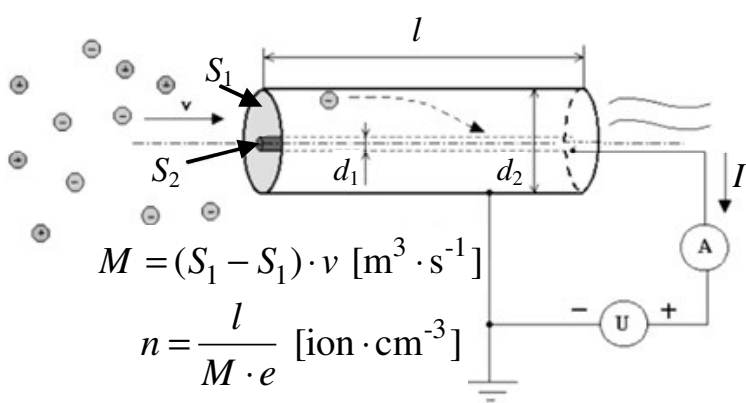

Fig. 1. Principle of gerdien condenser method.

Gerdien condenser shape ensures that the flow of air is laminar. Air flow turbulence can distort the accuracy of measurement. The surface of the electrodes is required to be as smooth as possible. The design of gerdien condenser is shown in Fig. 2.

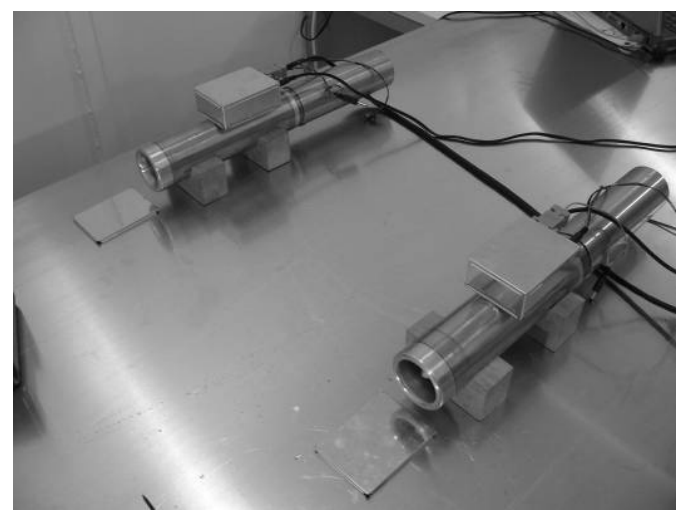

Fig. 2. Gerdien condenser design.

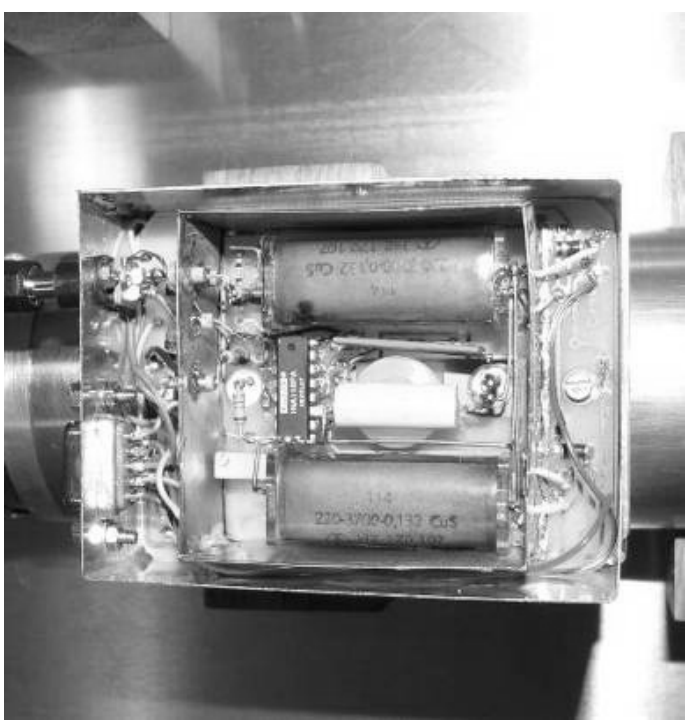

Fig. 3. Low level amplifier.

The current flowing through the gerdien condenser is due to the ion concentration. Current intensity depends on polarization voltage, on the dimension and parameters of gerdien condenser, and on ion concentration. The specific current range for the designed gerdien condenser is $10^{-10} \mathrm{~A}-10^{-13} \mathrm{~A}$. The low-level amplifier is realized with INA116. The design of the amplifier is shown in Fig. 3.

\section{NUMERICAL MODELING OF DESIGN, VERIFICATION}

It is possible to carry out analysis of a gerdien condenser model as a numerical solution by help of Finite element method (FEM). The electromagnetic part of the model is based on the solution of full Maxwell's equations. It was solved like simply electrostatic field. This results showed to new facts in gerdien condenser design [25]. New design of gerdien condenser was made with filter for the specific particles, Fig. 2.

\section{TESTS OF GERDIEN CONDENSERS}

The gerdien condenser design was tested according to the special measuring methodology [25]. The experiments are shown in Fig. 4 and Fig. 5.

\begin{tabular}{|c|c|c|c|c|c|}
\hline Meas. type & Mode & Fan & Voltage & Ion gener. & Air flow \\
\hline \multirow{4}{*}{ Absolute } & \multirow{4}{*}{ Testing A } & 0 & 0 & 0 & 0 \\
\hline & & 0 & 1 & 0 & 0 \\
\hline & & 1 & 0 & 0 & 0 \\
\hline & & 1 & 1 & 0 & 0 \\
\hline \multirow{7}{*}{ Diferential } & \multirow{4}{*}{ Testing A } & 0 & 0 & 0 & 0 \\
\hline & & 0 & 1 & 0 & 0 \\
\hline & & 1 & 0 & 0 & 0 \\
\hline & & 1 & 1 & 0 & 0 \\
\hline & \multirow{3}{*}{$\begin{array}{c}\text { Measurement } \\
\text { D }\end{array}$} & 0 & 0 & 0 & 0 \\
\hline & & 0 & 1 & 0 & 0 \\
\hline & & 1 & 1 & 1 & 1 \\
\hline
\end{tabular}

Table 1. Gerdien tube measurement sequence

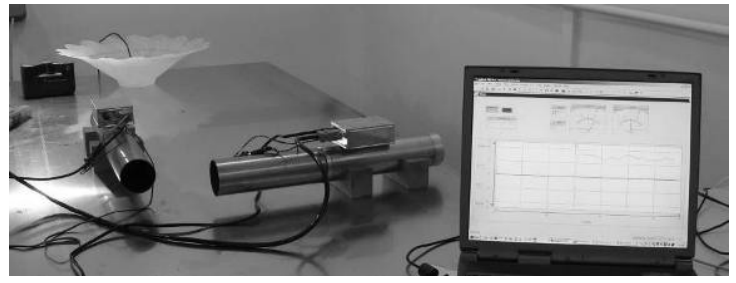

Fig. 4. Gerdien condenser measuring method-test by the electronic ion generator. 


\section{CONCLUSION}

The new design of gerdien condenser and the optimization of peripheral measuring devices have minimized the systematic error of measurement. The system allows measuring air ion concentration with a sensitivity $>50$ ions $/ \mathrm{cm} 3$. The ion mobility is in the interval $0.3-100 \mathrm{~cm}^{2} \mathrm{~V}^{-1} \mathrm{~s}^{-1}$. The system is used to measure ion field distribution in living and office spaces.

\section{Acknowledgement}

The paper were prepared within the framework of VUT Brno of the Czech Republic and with the support of the research plan MSM 0021630516 and grant GAAV No. B208130603.

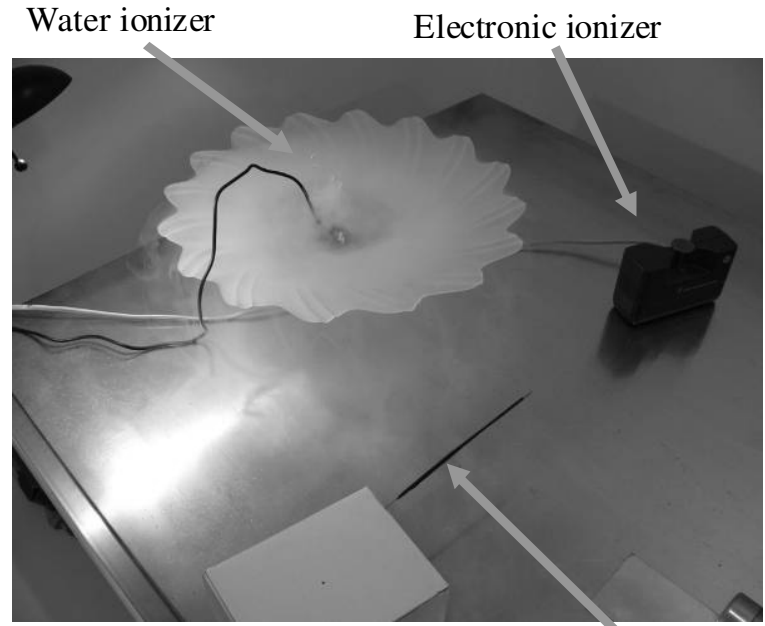

Aromastick

Fig. 5. Gerdien condenser measuring -test by water, electronic generator and aromastic.

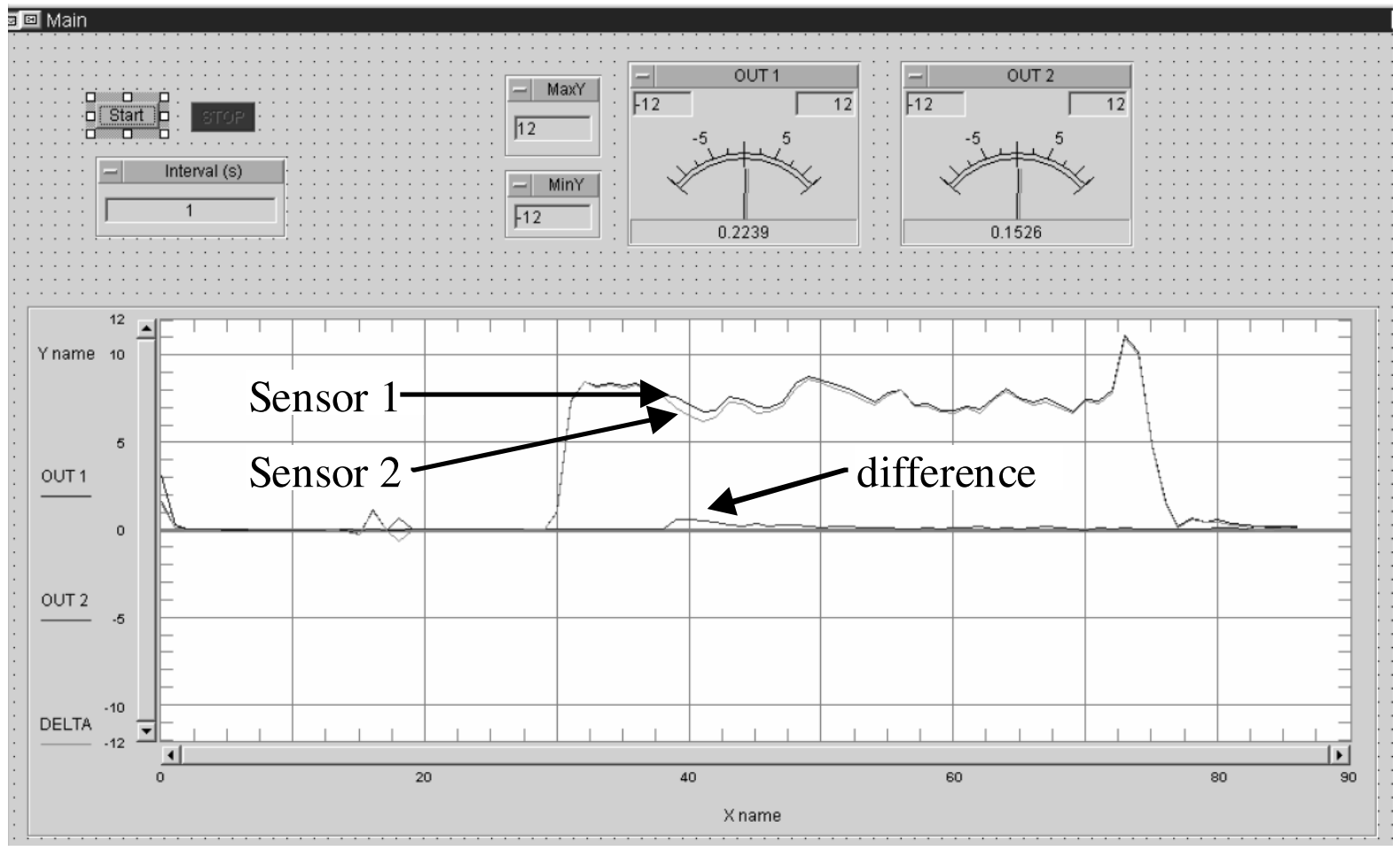

Fig. 6. Example results of differential measurement of the electronic negative ion generator.

\section{REFERENCES}

[1] S. M. Kinne, "A public health approach to evaluating the significance of air ions," Health Science Center at Houston, School of Public Health, Univ. Texas,, Houston, TX, May 1997.

[2] M. N. Kondrashova, E. V. Grigigorreko, A. N. Tikhonov, T. V. Sirota, A. V. Temnov, I. G. Stavrovskaya, N. I. Kosyakova, N. V. Lange, and V. P. Tikonov, "The primary physicochemical mechanism for the beneficial biological/medical effects of negative air ions," IEEE Trans. Plasma Sci., vol. 28, pp. 230-237, Feb. 2000.

[3] A. P. Krueger and E. J. Reed, "Biological impact of small ions," Science, vol. 193, no. 4259, pp. 1209-1213, Sept. 24, 1976.

[4] F. Soyka and A. Edmonds, The Ion EffectHow Air Electricity Rules Your Life and 
Health. New York: E. P. Dutton, 1977, pp. 1181.

[5] R. I. Kavet, Eds. Boca Raton, FL: CRC, 1987, ch. 9, pp. 1-538.

[6] J. R. Roth, "Industrial plasma engineering," in Principles. Philadelphia, PA: IOP, 1995, vol. 1, pp. $1-538$.

[7] A. Schutze, J. Y. Jeong, S. E. Babayan, J. Park, G. S. Selwyn, and R. F. Hicks, "The atmospheric-pressure plasma jet: A review and comparison to other plasma sources," IEEE Trans. Plasma Sci., vol. 26, pp. 1685-1694, Dec. 1998.

[8] B. Eliasson and U. Kogelschatz, "Nonequilibrium volume plasma chemical processing," IEEE Trans. Plasma Sci., vol. 19, pp. 1063-1077, Dec. 1991.

[9] M. Laroussi, "Biological decontamination by nonthermal plasmas," IEEE Trans. Plasma Sci., vol. 28, pp. 184-188, Feb. 2000.

[10] K. H. Seo, B. W. Mitchell, P. S. Holt, and R. K. Gast, "Bactericidal effects of negative air ions on airborne and surface salmonella enteritidis from an artificially generated aerosol," J. Food Protection, vol. 64, no. 1, pp. 113-116, 2001, [Online] Available: http://www.seprl.ars.usda.gov/bmitchell/status. htm.

[11] R. Zhang, T. Yamamoto, and D. S. Bundy, "Control of ammonia and odors in animal houses by a ferroelectric plasma reactor," IEEE Trans. Ind. Appl., vol. 32, pp. 113-117, Feb. 1996.

[12] H.W. Herrman, I. Henins, J. Park, and G. S. Selwyn, "Decontamination of chemical and biological warfare (CBW) agents using an atmospheric pressure plasma jet (APPJ)," Phys. Plasmas, vol. 6, pp. 2284-2289, May 1999.

[13] S. L. Daniels, "Engineered solutions for mitigation of IAQ problems," in Proc. 2nd NSF Int. Conf. Indoor Air Health, Miami Beach, FL, Jan. 29-31, 2001, pp. 243-249.

[14] "Control of VOCs and PM in indoor environments by air ionization, poster presentation, electromed 2001," in Proc. 2nd Int. Symp. Nonthermal Medical/Biological Treatments Using Electromagnetic Fields and Ionized Gases, Portsmouth, VA, May 20-23, 2001.

[15] "Applications of air ionization for control of VOCs and PM , paper \#918," in Proc. 94th Annu. Conf. Exhibition Air and Waste Management Assoc., Orlando, FL, June 24-28, 2001.
[16] S. L. Daniels and M. T. Fox, "Engineering design for indoor air environments: Perception vs. reality, Paper E-5," in Proc. 1st NSF Int. Conf. Indoor Air Health: Impacts, Issues, and Solutions, Denver, CO, May 3, 1999, pp. 6574

[17] S. L. Daniels and C. Frost, "Applications of negative air ionization for removal of volatile organic compounds (VOCs) and particulate matter (PM )," in Proc. 2nd NSF Int. Conf. Indoor Air Health, Miami Beach, FL, Jan. 2931, 2001, pp. 346-52.

[18] J. M. Charry and R. Kvet, Air Ions: Physical and Biological Aspects. Boca Ration, FL: CRC Press, 1987.

[19] A. L. Tchijevsky, Aeroionization: Its Role in the National Economy. Washington, DC: Office Naval Intell., 1960.

[20] L. I. Gerasimova, Lasers in Surgery and Therapy of Thermal Burns. Manual for Physicians (in Russian). Moscow, Russia: Medicine, 2000.

[21] A. L. Tchijevsky, A Manual for The Application of Ionized Air in Industry, Agriculture, and Medicine (in Russian). Moscow, Russia: Gosplanizdat, 1959.

[22] N. I. Goldstein and T. V. Arshavskaya, "Is atmospheric superoxide vitally necessary?," Z. Naturforsch, vol. 52, no. 5/6, pp. 396-404, May/Jun. 1997.

[23] S. L. Daniels, "On the ionization of air for removal of noxious effluvials," IEEE Trans. Plasma Sci., vol. 30, no. 4, pp. 1471-1481, Aug. 2002.

[24] Fiala. P, Bartusek. K, Vojtek. T, Skoupil. T," Accuracy of air ion field measurement ", PIERS2006, ISSN 1559-9450, Boston, USA.

[25] Fiala. P, Bartusek. K, Vojtek. T, Skoupil. T," Accuracy of air ion field measurement ", PIERS2007, ISSN 1559-9450, Beijing, CHINA.

[26] Kadlecova. E, Behunek. I, Fiala. P, " Numerical model of optimization lead-acid accumulator grids ", PIERS2007, ISSN 15599450, Beijing, CHINA. Numerical model of inductive flow meter.

[27] Fiala. P, Jirku. T, Behunek. I, " Numerical model of inductive flowmeter ", PIERS2007, ISSN 1559-9450, Beijing, CHINA. 